\title{
A Survey on Risk Management in Electricity Markets
}

\author{
Min Liu, Felix F. Wu, Fellow, IEEE and Yixin Ni, Senior Member, IEEE
}

\begin{abstract}
In the electricity market, electricity prices are substantially more volatile than any other commodity price. Confronting with this extreme price volatility, more and more market participants are recognizing the importance and necessity of risk management. This paper introduces some risk management techniques which are widely used in the financial literature and their applications in the electricity market. These techniques include hedging, portfolio optimization, risk measurement and asset valuation. Furthermore, this paper also introduces several additional techniques of risk management which are developed to deal with the specialties of electricity, electrical assets and electricity market. Based on the literature survey, some suggestions for future work are offered.
\end{abstract}

Index Terms-- Electricity market, Hedging, Portfolio optimization, Risk management

\section{INTRODUCTION}

$\mathrm{G}$ lobal deregulation in the electrical power industry in the past decade has introduced the concept of a competitive electricity market. In this new environment, electricity is traded the same way as other commodities. However, because electricity cannot be stored and its transmission is limited by physical and reliability constraints, electricity prices are substantially more volatile than any other commodity price. Statistical data of US department of Energy indicates that in the US, the average annual volatility of electricity is $359.8 \%$ while Natural Gas \& Petroleum, Financial, Metals, Agriculture, and Meat are just 48.5\%, 37.8\%, 21.8\%, 49.1\% and $42.6 \%$ respectively[1].

Confronting with this extreme price volatility, market participants are facing trading risks, and therefore need to find ways to protect their benefits. Especially after observing the market anomalies in the US, e.g., the 1998 substantial price volatility of Midwest and 2000 California electricity crisis, more and more market participants are recognizing the importance and necessity of risk management. Nowadays, risk management is a hot topic both in power industry and in academic community. IEEE PES has organized two tutorials on Risk Assessment and Financial Management: one is in

Min Liu is with the Faculty of Electrical Engineering, Guizhou University, P R China (e-mail: ee.mliu@gzu.edu.cn )

Felix F. Wu and Yixin $\mathrm{Ni}$ are with the Department of Electrical and Electronic Engineering, The University of Hong Kong, Hong Kong (e-mail: ffwu@eee.hku.hk and yxni@eee.hku.hk).

This work is supported by Guizhou University of Technology, Guizhou, China, under Grant GUT2004-014.
1999 winter meeting and the other is in 2002 summer meeting. Many other conferences and symposiums have devoted time to risk management in the electricity market.

In what follows, Section II introduces the definition of risk and associated risks in the electricity market. Focusing on the risk of electricity price, Section III introduces the risk management techniques and their application in electricity markets. Finally, Section IV draws a short conclusion about the status quo of risk management in electricity markets and gives some suggestions for future work.

\section{RISK IN ELECTRICITY MARKET}

In the dictionary, the basic definition of risk is the possibility of suffering harm or loss; danger or hazard. In the electricity market, market participants such as Generation companies and Distribution companies concern about their benefits (quantified with Profits or Returns) which are influenced by many uncertain factors such as electricity price, production/operation cost, load demand, unit outage, power system operation conditions etc. These uncertainties bring about the possibility of both improving and decreasing benefits. In other words, uncertainty means opportunity and risk. In this paper, risk is therefore, defined as the hazard to which a market participant is exposed because of uncertainty.

Trading in the electricity market involves several types of risks such as Regulatory Risk, Credit Risk, Liquidity Risk, Operational Risk, Delivery Risk, and Price Risk. With the consideration of one or several types of risks, some literatures have discussed the risk management issue from different points of view which include Gencos [2], power systems [3][5], power suppliers [6], [7], consumers [8], marketers [9] and resource planning [10]. This paper doesn't intent to cover all the aspects of risk management in the electricity market but focuses on the risk management in energy trading with price risk into consideration.

\section{RISK MANAGEMENT}

Risk management is the process of achieving the desired balance of risk and return through a particular trading strategy. In the financial literature, risk management at least includes two aspects: risk control and risk assessment. There are two means to control risk. One is "hedging" which is a technique to offset particular source of risk [11]. The other means of risk control is "diversification". Diversification means to trade energy through different trading approaches. In the energy 
market, both physical trading approach (e.g. spot market, bilateral contract market) and financial trading approach (e.g. futures contracts, options, swaps etc.) are provided ${ }^{1}$. A combination of these trading approaches is defined as a portfolio and corresponding risk-control methodology is named portfolio optimization. Therefore, Hedging and Portfolio Optimization are two risk-control means/techniques for energy trading.

As for another aspect of risk management, i.e., risk assessment, Value at Risk ( $\mathrm{VaR})$ is a common measurement for the risk exposure of financial portfolios and has been applied in electricity market. Furthermore, other methods have been proposed to value assets in the electricity market.

Risk management techniques are summarized in Fig. 1.

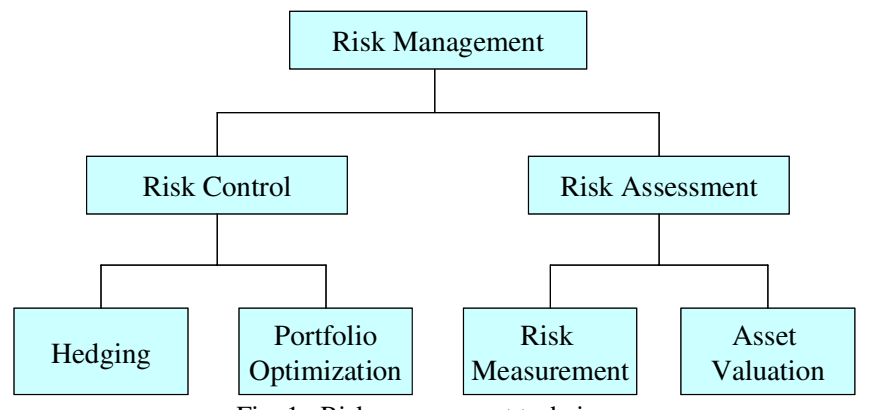

Fig. 1. Risk management techniques

\section{A. Hedging}

Hedging is buying of a derivative to offset the risk of a cash position, which is the amount of energy owned. Derivatives are financial instruments (contacts) that do not represent ownership rights in energy but, rather, derive their value from the value of some other underlying commodity or other asset. When used prudently, derivatives are efficient and effective tools for isolating financial risk and "hedging" to reduce exposure to risk. The most commonly used derivative contracts include Forward Contracts, Futures Contracts, Options and Swaps etc.

\section{(a) Forward contracts}

A forward contract is a contract that obligates the holders to buy or sell an asset for a predetermined delivery price at a predetermined future time [12]. The contract is an over-thecounter (OTC) ${ }^{2}$ agreement between two companies. No money changes hands when contract is first negotiated and it is settled at maturity. Under a forward contract, one party is obligated to buy and the other sell, a specified quantity of a specified commodity at a fixed price on a given date in the future. At the maturity of a forward contract, the seller will deliver the commodity and buyer will pay the purchase price. The terms and conditions of forward contracts are not

\footnotetext{
${ }^{1}$ Physical trading approach refers to the trading approach in which actual physical energy are traded while financial trading approach only involves financial settlement, no actual physical energy are traded through this approach.

${ }^{2}$ OTC is a kind of derivatives market in which non-standard products (e.g., contracts) are traded. Trades on the OTC market are negotiated directly through dealers.
}

standardized but are negotiated to meet the particular business, financial or risk management needs of the parties to the contract. In addition to the ordinary forward contracts, the literature has proposed two additional types of electricity forward contracts which will be introduced in the section of special electricity contracts.

\section{(b) Futures}

A futures contract obligates each party to buy or sell a specific amount of commodity at a specified price. Buyers and sellers of futures contracts deal with an exchange, not with each other. In contrast to forward contracts, except contract price, the exchange standardizes the terms and conditions of the futures contracts such as the unit trading amount, delivery time and locations etc. In most case, physical delivery does not take place, and the futures contract is closed by buying or selling a futures contract on or near the delivery date. In other words, most futures contracts are used as financial vehicles, with no intention of taking delivery of the commodity. Less than $2 \%$ of futures contracts end in delivery [13].

In practice, Electricity futures contracts were employed in Norway in 1995 followed by the United States and New Zealand in 1996 and until now, Norway, Sweden, Finland, New Zealand, Australia, and the US have had futures contracts for electricity.

From research point of view, Blackmon [14] first reported an interesting initial study on the development of a futures market in electrical energy. Tanlapco [15] discussed the basic concepts and techniques for hedging of financial risks using the futures contracts in an electricity market, and concluded that the use of electricity futures contracts is superior to using other related futures contracts such as crude oil base on the standard deviation or risk of the values of the hedging positions. For the policy of selling electricity in the spot market, the effect of futures contracts is evaluated in [16]. But Collins [17] argues that the current futures market for California electricity market is not working, which is part of the reason for the well known California electricity crisis, because electricity is very much different from other commodities to require changes in the delivery process specified in the futures contract. In [17], Collins provides a simple explanation of the economics of electricity hedging and shows why the unique characteristics of electric power (i.e., electric power cannot be stored and electricity demand varies from minute to minute) make risk management more complex than for other commodities. Then he proposes some modifications to the futures contract for electric power that reflects these unique characteristics. These modifications are to cerate contracts which allowed the participants to continue resettlement through the delivery month based on some established spot market. This could be thought of as delivery to a price index. Instead of taking physical delivery of power, the participants would agree to make financial transactions according to the terms actual average daily spot prices that occur during the delivery month. It was demonstrated that this 
unique resettlement mechanism would make the futures contract more useful for hedgers on both sides of the market.

\section{(c) Options}

An option is a contract that gives the buyer of the contract the right to buy (a call option) or sell (a put option) at a specified price (the "strike price') over a specified period of time. The right to perform a financial transaction has a financial value called a premium. The buyer of the option pays a premium for the right (but not the obligation) to buy or sell the underlying asset. The underlying asset of an option could be stocks, currencies, debt instruments, commodities, or futures contracts.

Whether the option is sold on an exchange or on the OTC (over-the-counter) market, the buyer pays for it up front. Options are used successfully to put floors and ceilings on prices; however, they tend to be expensive due to the payment of premium.

\section{(d) Swaps}

Swaps (also called Contracts for Differences-CfDs) are created in part to give price certainty at a cost that is lower than the cost of options. A swap contract is an agreement between two parties to exchange a series of cash flows generated by underlying assets. No physical commodity is actually transferred between the buyer and seller. The contracts are entered into between the two partners, or principals, outside any centralized trading facility or exchange and are therefore characterized as OTC derivatives. In the Nordic region, CfDs are used to hedge against the difference between the two uncertain prices (area price and system price) [18], while in the British market, against the difference between the spot price and a pre-defined reference price or price profile [19].

Many of the benefits associated with swap contracts are similar to those associated with futures or options contracts. That is, they allow users to manage price exposure risk without having to take possession of the commodity. They differ from exchange-traded futures and options in that, because they are individually negotiated instruments, users can customize them to suit their risk management activities to a greater degree than is easily accomplished with more standardized futures contracts or exchanged-traded options.

Although swaps can be highly customized, the counterparties are exposed to higher credit risk because the contracts generally are not guaranteed by a clearinghouse as the exchange-traded derivatives. In addition, customized swaps generally are less liquid instruments, usually requiring parties to renegotiate terms before prematurely terminating or offsetting a contract.

(e) Special electricity contracts

Two additional types of electricity forward contracts are proposed in the literature.

Kaye et al [20] proposed an Updated Forward Contract with the contract prices set by the suppliers. Consumers, however, can regularly update their contracts before the delivery date. This enables the forward contract price to be regularly updated as the spot time is approached so that it contains the most recent system information. It is demonstrated that the contracts are particularly useful for coordinating supply and demand side operations decisions under spot pricing. They allow inflexible or risk-averse participants to lock in a suitable contract price for electrical energy and avoid the adverse effects of price fluctuations, while not removing the incentives for more flexible participants to respond to spot prices. However, this kind of contract does not provide information or incentives for investment decisions.

With two financial contractual instruments, futures and options, Gedra et al [21], [22] construct Optional Forward Contracts which include the callable forward and the puttable forward contract. A callable forward contract is a bundle of a long, or purchased, forward contract and a short, or sold, call option. That is, a consumer who purchases a callable forward has purchased a forward contract and then sold a call option to the utility. This means that the utility can interrupt the consumer's service by exercising the call option and paying the consumer the strike price of the call instead of delivering the energy. While a puttable forward contract is a bundle of a forward contract and a put option. Thus the electricity producer who sells a puttable forward has sold a forward contract but has also sold to the utility the right to interrupt delivery of the energy, in which case the producer must buy back the energy by paying the strike price to the utility. It is shown that a market mechanism based on these contracts has two useful properties. The first one is obtaining allocative efficiency while removing the negative impact of spot pricing in risk-averse market participants. The second property lies on the information revelation, i.e., market participants can have the appropriate incentives to reveal their preferences and costs to the agent (utility). This information can be used by the utility to predict changes in supply and demand in response to a price change, as well as for system planning purposes.

\section{(f) Instruments Valuation}

Unlike many commodities, electricity is expensive to store. As a result, it is consumed the instant it is produced. Standard risk management textbooks provide numerous formulas for valuation of derivative contracts on storable assets, but none of that apply to non-storable commodities. Some researchers have made investigation on how to value flexible electricity contracts [23] and value standard electricity derivatives [24].

In [23], based on the principle of no-arbitrage, variables of the contracts (i.e., contract volume and price) are used to determine arbitrage opportunities and the price of contracts. In [24], Deng derived prices of various electricity derivatives such as futures, forward, call option, cross commodity spread option, based on mean-reversion jump-diffusion models of 
electricity spot price, with the use of Fourier transform methods ${ }^{3}$.

\section{B. Portfolio optimization}

A trading portfolio is a combination of all available trading approaches. Portfolio optimization refers to optimally allocate total trading energy among multiple trading approaches with the aim of maximizing participants' benefits (profits or returns) and minimizing the corresponding risk. Except simulation with Monte Carlo Method (e.g., [30]), two types of methodologies can be adopted to solve the portfolio optimization problem: Decision Analysis and Modern Portfolio Theory.

\section{(a) Decision Analysis}

Decision Analysis (DA) [31] is based on the assumption that the attractiveness of alternatives should depend on the decision-maker's judgment about the likelihood (probabilities) of the possible consequences of each alternative course of action and his or her preference for the possible consequences of each action. What makes DA valuable is the formal incorporation of these factors into the analysis of a problem. Subjective probability, the incorporation of data, experts' knowledge, models, and so on are used to quantify judgment about the likelihood of various consequences. Utility theory is used to quantify consequences.

In the decision model, generally, two types of formats, namely the decision matrix and the decision tree are used to represent all the available information in a compact and clear form, which would enhance the understanding of the problem and facilitate making the best decision. The decision criterion used most widely is the maximum expected-monetary-value (EMV) criterion. Suppose that $d_{i j}$ denotes the monetary gain of the $\mathrm{j}^{\text {th }}$ consequence associated with alternative $\mathrm{i}$ and that $p_{i j}$ is the corresponding probability; then the expected monetary gain of the $\mathrm{i}^{\text {th }}$ alternative is $E\left(A_{i}\right)=\sum_{j} p_{i j} d_{i j}$. The optimal alternative according to this max EMV criterion is the one whose monetary value is $d\left(A_{o p t}\right)=\max _{i} \sum_{j} p_{i j} d_{i j}$.

The DA approach has been applied in some investigations on portfolio optimization. For example, in [32], [33], DA is used for a Generation company to make transaction schedule such as contact selection. Siddiqi [34] applied the DA to a long-term management of power portfolio.

The disadvantages of the DA lie in two aspects. Firstly, DA does not explicitly consider decision-makers' risk aversions. Secondly, it does not take into consideration the correlation among alternatives, therefore, provides no approach to risk control/mitigation. These disadvantages of the DA are just the advantages of the Modern Portfolio Theory.

\footnotetext{
${ }^{3}$ Actually, the key to value electricity flexible contracts and standard derivatives is modeling electricity spot price. A significant amount of literature has emerged on this topic [23]-[29].
}

(b) Modern Portfolio Theory

The Modern Portfolio Theory (MPT) [11], [35] is principles underlying analysis and evaluation of rational portfolio choices based on risk-return trade-offs and efficient diversification. In other words, MPT is an approach to measuring the risk of an asset, quantifying trade-off between risk (properly measured) and expected return, and finally forming an optimal portfolio of assets. In the MPT, the risk of an asset is measured with the variance/standard deviation of its return; the trade-off between risk and expected return is quantified with a utility function, i.e., $U=E(r)-0.5 A \sigma^{2}$, where $E(r)$ and $\sigma^{2}$ are the expected value and variance of a portfolio's return respectively; $A$ is an index of the decisionmaker's risk-aversion; $U$ is the utility value of the portfolio. A portfolio with the highest utility value is the optimal portfolio.

MPT has been widely used in the financial literature for portfolio selection. In the literature of electricity market, it has been applied to solve the allocation of trading energy aim at maximizing profit and minimizing associated risk. In [36], Liu proposed a layered framework of risk management for energy trading by Generation companies in which MPT is adopted for energy allocation among physical trading approaches.

\section{Risk measurement}

In the financial literature, one of the popular techniques of risk measurement is Value at Risk (VaR). The Global Derivatives Study Group, a former promoter of VaR, defines $\mathrm{VaR}$ as "the expected loss for an adverse market movement with a specified probability over a particular period of time." Essentially, VaR is a monetary value that the portfolio will lose less than that amount over a specified period of time with a specified probability. For example, a one-day $95 \%$ VaR of $\$ 500,000$ indicates that the portfolio is expected to lose 95 days out of 100 days an amount less than $\$ 500,000$. Therefore, one reason for the rapid acceptance of $\mathrm{VaR}$ as a risk measurement tool is that it provides a measurement of the maximum change in value of a portfolio over a set time frame to a given certainty assuming normal market conditions. The VaR value represents a statistical estimate of the frequency distribution of changes in value of a portfolio for a desired time range based on historical data [37].

There are numerous methods to calculate VaR. These methods use different assumptions and techniques, since VaR calculations are very sensitive to assumptions and data. Although there is little consensus on the preferred method of VaR calculation, widely accepted methods include Historical Methods, Historical Simulation Approach, Analytical Methods and Monte Carlo Simulation [31]. The Gloriamunidi web site [38] contains a wealth of information on the various models currently in use.

As for the application of $\mathrm{VaR}$ in electricity market, the chapter ten [39] titled "Value at Risk for Power Markets" by K. Leong and R. Siddiqi establishes a framework for using 
VaR to quantify the risk of a single electricity contract and then of a portfolio of contracts. This formulation assumes, in part, that fundamental price follows a normal distribution as opposed to a mean-reverting process. R. Dahlgren et al [40] claimed that there are differences between a VaR calculation for a single electricity contract using the centrally cleared market dispatch rules and a VaR calculation using only historical price clearing data, with a 5-bus example from the PJM training system. Denton et al [41] discussed the application of $\mathrm{VaR}$ in intermediate term risk management of generating plants. While Dahlgren et al [2] demonstrated how to use VaR to value a trading portfolio with an example of electricity market scenario (VaR is calculated with historical data method).

\section{Asset valuation}

In the literature, electricity asset valuation is mainly focusing on the valuation of generation plants [41], [42]-[44]. Two approaches have been proposed: financial option model [42] and real option model [43], [44].

\section{(a) Financial option model}

A power plant converts a particular fuel to electricity. This conversion involves two commodities with different market prices. Therefore, owing a power plant can be regarded as the electricity price less the product of the heat rate associated the generator and the fuel price. When the electricity price is high but the fuel price is low such that their ratio is greater than the unit's heat rate, the power plant should run to capture the profit due to the price spread, and vice versa (since the power plant profits more, when the spread is greater, it is a call option in this sense).

Deng [42] proposed a Spark Spread Options based model to value generation assets. Firstly, a methodology for valuing electricity derivatives by constructing replicating portfolios with futures contracts and the risk free asset is presented; Then, the methodology is used to derive valuation formula for spark spread options when the prices of the underlying assets follow either geometric Brownian notion or mean reverting processes; Finally, the valuation result was in turn used to construct real options based valuation formula for generation assets.

However, this Spark Spread Options based model fails to represent the non-linear heat rate characteristics of different generating equipment and requires an average heat rate representation. In other words, the model fails to consider the physical constraints on unit operations as well as associated costs - rate limits, cycle times, start up costs, and limits on total unit cycles in a maintenance period. As a result, [41] argued that Spark spread models usually "overvalue" a plant by $10-30 \%$. When used to value an asset for long term financing, they can produce overly optimistic valuations.

\section{(b) Real option model}

Real option model takes unit commitment constraints into consideration. The valuation problem of power plants is formulated as a multi-stage stochastic problem. For the shortterm valuation on generation asset, this dynamic stochastic problem is solved with Monte Carlo simulation method in [43]. For long-term (e.g. multi-year) valuation problem, [44] adopts the Multi-level trinomial tree-trinomial forestmethodology.

\section{CONCLUSION}

This paper introduces the risk management techniques which are adopted in the electricity market. From the literature survey in this paper, we see that a significant amount of literature focused on (1) the hedging of spot price risk with individual instruments (e.g., forward contracts, futures contracts etc.) and instruments pricing; and (2) risk measurement of portfolios and generation assets valuation. Very few researches have been directed towards portfolio optimization. From risk management point of view, a system which incorporates risk control and risk measure is preferred. Ref. [36] has made the first step in this area using the Modern Portfolio Theory and Value at Risk. Further works are needed to investigate how to synthetically apply these financial techniques to the risk management in electricity markets and further develop specific techniques which are applied to electricity markets.

\section{REFERENCE}

[1] Energy Information Administration, "Derivatives and Risk Management in the Petroleum, Natural Gas, and Electricity Industries," U.S. Department of Energy, Washington, Tech. Rep, SR/SMG/2002-01, Oct. 2002.

[2] R. Dahlgren, C. C. Liu, and J. Lawarree, "Risk assessment in energy trading," IEEE Trans. Power Systems, vol. 18, Issue 2, pp. 503-511, May 2003.

[3] Mario V.F. Pereira, M. F. McCoy, and H. M. Merrill, "Managing risk in the new power business," IEEE Computer Applications in Power, vol. 13, Issue 2, pp. 18-24, April 2000.

[4] J. L. Higle, and S. W. Wallace, "Managing risk in the new power business: a sequel," IEEE Computer Applications in Power, vol. 15, Issue 2, April 2002.

[5] S. Oren, "Market Based Risk Mitigation: Risk Management vs. Risk Avoidance," in Proc. White House OSTP/NSF Workshop on Critical Infrastructure Interdependencies, Washington DC, June 14-15, 2001.

[6] D. Ruiu and M. Swales, "Quantify and mitigate power-purchase risks," IEEE Computer Applications in Power, vol. 11, Issue 3, pp. 54-59, July 1998.

[7] G.V. Welch, M. V. Engel, and H.W. Adams, "Acquiring energy resources in a competitive market," IEEE Power and Energy Magazine, vol. 1, Issue 3, pp. 36-42, May-June 2003.

[8] P.R. Cunningham and V.E. Prater, "Risk management for power supplies in a deregulated world," presented at the Cement Industry Technical Conference 2003, Conference Record. IEEE-IAS/PCA 2003, pp. 109-114, May 4-9, 2003.

[9] F. P. Sioshansi, "The emergence of trading and risk management in liberalized electricity markets," Energy Policy, vol.30, Issue 6, pp. 449459, May 2002.

[10] C.J. Andrews, "Evaluating risk management strategies in resource planning," IEEE Trans. Power Systems, vol. 10, Issue 1, pp. 420-426, Feb. 1995.

[11] Z. Bodie, A. Kane, and A. J. Marcus, Investments, $4^{\text {th }}$ ed., Chicago: Irwin/McGraw-Hill, 1999.

[12] J. C. Hull, Options, Futures, \& Other Derivatives, $4^{\text {th }}$ ed., Upper Saddle River, N.J.: Prentice Hall, 1999.

[13] J. E. Treat, Energy Futures: Trading Opportunities for the 1980s, Tulsa: PennWell Books, 1984. 
[14] B. G. Blackmon, "A Futures Market for Electricity: Benefits and Feasibility," Havard Uni. Kennedy School of Gov., En. \& Env. Policy Centre, Disc. Paper E-85-07, July 1985.

[15] E. Tanlapco, J. Lawarree, and C. C. Liu, "Hedging with futures contracts in a deregulated electricity industry," IEEE Trans. Power Systems, vol. 17, Issue 3, pp. 577-582, Aug. 2002.

[16] R. Bjorgan, C. C. Liu and J. Lawarree, "Financial risk management in a competitive electricity market," IEEE Trans. Power Systems, vol. 14 Issue 4, pp. 1285-1291, Nov. 1999.

[17] R. A. Collins, "The economics of electricity hedging and a proposed modification for the futures contract for electricity," IEEE Trans. Power Systems, vol. 17, Issue 1, pp. 100-107, Feb. 2002.

[18] T. Kristiansen, "Congestion management, transmission pricing and area price hedging in the Nordic region," Electrical Power and Energy Systems, vol.26, pp.685-695, 2004.

[19] A. Powell, "Trading Forward in an Imperfect Market: The Case of Electriicty in Britain," The Economic Journal, vol. 103, No. 417. pp. 444453, Mar. 1993.

[20] R. J. Kaye, H. R. Outhred, and C. H. Bannister, "Forward contracts for the operation of an electricity industry under spot pricing," IEEE Trans. Power Systems, vol. 5, Issue 1, pp. 46-52, Feb. 1990.

[21] T. W. Gedra, "Optional forward contracts for electric power markets," IEEE Trans. Power Systems, vol. 9, Issue 4, pp. 1766-1773, Nov. 1994.

[22] T. W. Gedra and P. P. Varaiya, "Markets and pricing for interruptible electric power," IEEE Trans. Power Systems, vol. 8, Issue 1, pp. 122-128, Feb. 1993.

[23] R. Bjorgan, H. Song, C. C. Liu, and R. Dahlgren, "Pricing flexible electricity contracts," IEEE Trans. Power Systems, vol. 15, Issue 2, pp. 477-482, May 2000.

[24] S. J. Deng, "Pricing electricity derivatives under alternative stochastic spot price models," in Proc. the 33rd Annual Hawaii International Conference on System Sciences, pp. 1313-1322, Jan 4-7, 2000.

[25] V. Kaminski, "The Challenge of Pricing and Risk Managing Electricity Derivatives," The US Power Market, pp. 149-171, Risk Publications, 1997.

[26] G. Barz, and B. Johnson, "Modeling the Prices of Commodities that are Costly to Store: the Case of Electricity," in Proc. the Chicago Risk Management Conference, Chicago, May 1998.

[27] S. Deng, "Stochastic Models of Energy Commodity Prices and their Applications: Mean-Reversion with Jumps and Spikes," Univ. Calif. Energy Inst., working paper PWP-073, 2000.

[28] P. Skantze, M. Ilic, and J. Chapman, "Stochastic modeling of electric power prices in a multi-market environment," in Proc. IEEE Power Engineering Society Winter Meeting, vol. 2, pp. 1109-1114, 23-27 Jan. 2000.

[29] P. Skantze, A. Gubina, and M. Ilic, "Bid-based Stochastic Model for Electricity Prices: The Impact of Fundamental Drivers on Market Dynamics," Energy Laboratory of Massachusetts Institute of Technology, Energy Laboratory Publication \#MIT_EL 00-004, Nov. 2000.

[30] I. Vehviläinen and J. Keppo, "Managing electricity market price risk," European Journal of Operational Research, vol. 145, Issue 1, pp. 136147, 16 February 2003.

[31] G. Anders, R. Entriken, and P. Nitu, Risk Assessment and Financial Management, Tutorial, IEEE Power Engineering Society Winter Meeting 1999.

[32] G. B. Sheble, "Decision analysis tools for GENCO dispatchers," IEEE Trans. Power Systems, vol. 14, Issue 2, pp. 745-750, May 1999.

[33] J. Kumar and G. Sheblé, "A decision analysis approach to the transaction selection problem in a competitive electric market," Electric Power Systems Research, vol. 38, Issue 3, pp. 209-216, Sep. 1996.

[34] S. N. Siddiqi, "Project valuation and power portfolio management in a competitive market," IEEE Trans. Power Systems, vol. 15, Issue 1, pp. 116-121, Feb. 2000.

[35] E. J. Elton, M. J. Gruber, S. J. Brown and W. N. Goetzmann, Modern Portfolio Theory and Investment Analysis, $6^{\text {th }}$ ed., New York: John Wiley \& Sons, 2003.

[36] Liu Min, "Energy Allocation with Risk Management in Electricity Markets," PhD dissertation, Dept. Electrical and Electronic Engineering, The University of Hong Kong, 2004.

[37] P. Jorion, Value at Risk, New York: McGraw-Hill, 1997.

[38] [Online]. Available: http://www.gloriamundi.org.
[39] P. C. Fusaro, Energy Risk Management: Hedging Strategies and Instruments for the International Energy Markets, New York: McGrawHill, 1998.

[40] R. Dahlgren, C. C. Liu, and J. Lawarree, "Using market simulation to manage price risk in a centrally cleared market," in Proc. IEEE Power Engineering Society Summer Meeting, vol. 2, pp. 1261-1263, 18-22 July 1999.

[41] M. Denton, A. Palmer, R. Masiello, and P. Skantze, "Managing market risk in energy," IEEE Trans. Power Systems, vol. 18, Issue 2, pp. 494 502, May 2003.

[42] S. J. Deng, B. Johnson, and A. Sogomonian, "Spark spread options and the valuation of electricity generation assets," in Proc. the 32nd Annual Hawaii International Conference on System Sciences, 5-8 Jan. 1999.

[43] C. L. Tseng and G. Barz, "Short-term generation asset valuation," in Proc. the 32nd Annual Hawaii International Conference on System Sciences, 58 Jan. 1999.

[44] P. Skante, P. Visudhiphan, and M.D. Ilic, "Valuation of Generation Assets with Unit Commitment Constraints under Uncertain Fuel Prices," MIT Energy Laboratory Technical Report EL 00-006, MIT, November 2000.

\section{BIOGRAPHIES}

Min Liu She received her $\mathrm{Ph}$. D. degree in electrical engineering from the University of Hong Kong. She is now associate professor at Electrical Engineering Institute, Guizhou University, P.R. China. Her research interests are electric energy industry restructuring, power market and risk management.

Felix F. Wu (Fellow, IEEE) received his $\mathrm{Ph}$. D. degree from University of California at Berkeley (UCB). He is currently Philip Wong Wilson Wong Professor in Electrical Engineering at the University of Hong Kong, and Professor Emeritus at the Department of Electrical Engineering and Computer Sciences, UCB.

Yixin Ni (S. M. IEEE) She received her B. Eng., M. Eng., and Dr. Eng. degrees all in electrical engineering, Tsinghua University, China. She was former professor and director of National Power System Lab, Tsinghua University and now with the University of Hong Kong. Her research interests are power system stability and control, FACTS, AI tech. applications in power systems and power markets. 